\title{
Hypothyroidism in Nephrotic Syndrome in Children
}

\author{
1. Vidhi Sahni ${ }^{2}$.Sanjiv Nanda, ${ }^{3}$ Virender kumar Gehlawat, ${ }^{4}$ Geeta Gathwala \\ 1 MD Pediatrics, 2 senior professor and head unit II, 3 Assistant professor department of pediatrics, 4 senior \\ professor and HOD pediatrics.
}

\begin{abstract}
:
Background: This prospective observational study was conducted to make a comparative evaluation of thyroid status in children suffering from nephrotic syndrome before and after remission.It was carried over from June 2012 to December 2013 at Department of Paediatrics, Pt. B D. Sharma PGIMS, Rohtak. Objective: To find out the thyroid function of nephrotic children during nephrosis and remission and to know whether thyroid supplementation is required or not in children with nephrotic syndrome. Methods: The present study was carried out on 35 children of age between 1-8 years of nephrotic syndrome coming to the hospital.Thyroid profile was done during relapse and remission. Results: Serum T3 and T4 level during nephrosis and during remission were within normal limits. But TSH level is significantly higher during nephrosis which normalizes during remission 6 weeks later $(8.93 \pm 3.15$ vs. $5.77 \pm 0.65 \mathrm{MIU} / L, p=0.002)$. Thyroxine supplementation is not required as it results in subclinical hypothyroidism..The study showed a negative correlation between serum albumin and serum TSH $(r=-0.480, p=<0.05)$. Conclusions:This study concluded nephrotic syndrome commonly have a state of subclinical hypothyroidism during proteinuria although they are clinically euthyroid which improves with remission and needs no treatment.
\end{abstract}

Keywords: hypothyroidism, nephrotic syndrome, T3,T4,TSH.

\section{Introduction}

The interactions between kidney and thyroid functions are known for years. ${ }^{[1]}$ Thyroid hormones $(\mathrm{TH})$ are necessary for growth and development of the kidney and for the maintenance of water and electrolyte homeostasis. Thyroid hormones, thyroxine (T4) and triiodothyronine (T3) play important roles in the maturation and development of the skeleton and affect endochondral calcification and the entire process of cartilage growth. ${ }^{[2]} \mathrm{On}$ the other hand, kidney is involved in the metabolism and elimination of thyroid hormone. ${ }^{[3,4]}$ Thyroid hormone in the circulation is bound to proteins, mainly thyroid binding globulin, prealbumin and albumin. ${ }^{[5]}$ Nephrotic syndrome results in urinary loss of intermediate sized plasma proteins $(40-$ $200 \mathrm{kDa})^{[6]}$ and hormone binding proteins such as thyroxine binding globulin (TBG), transthyretin and albumin leading to reduction in thyroid hormones. ${ }^{[7,8]}$

MattooTK has shown the existence of a hypothyroid state in some infants with NS; they recommended routine thyroid screening and early replacement therapy. ${ }^{[9]}$ Ito $\mathrm{S}$ et al. has shown evidence of mild hypothyroidism in children with untreated NS, partly because of losses of T4, T3, free T4, free T3 and TBG in the urine. ${ }^{[10]}$

B. U. Sawant et. al opined that nephrotic syndrome patients have an increased risk of subclinical hypothyroidism. Thyroid function returns to the normal when the non thyroid illness is resolved ${ }^{[1]}$ Gilles et al reported that abnormalities in thyroid function are seen in patients with proteinuria. Specifically,TSH levels were higher in patients with proteinuric renal diseases when compared with controls. ${ }^{[12]}$ Ilgesias $p$ in his study concluded that proteinuria results in loss of thyroid hormone stimulating TSH production. Thyroid function returns to the normal when the nonthyroid illness is resolved. ${ }^{[13]}$ AfrozS et al in 2011 found that mean value of serum T3 and T4 in children during nephrosis were within normal limit however mean value of thyroid stimulating hormone (TSH) was higher than normal level during nephrosis.This study concluded that Nephrotic syndrome commonly have a state of mild or subclinical hypothyroidism during proteinuria although they are clinically euthyroid. ${ }^{[14]}$ our study was done to find out the thyroid status of NS children during nephrosis and to compare the thyroid function of these children before and after steroid treatment to see whether it is persistent and needs thyroxine therapy.

\section{Methods}

This observational prospective study was carried out on 35 children of age between 1-8 years of either sex of nephrotic syndrome coming to Department of Paediatrics, Pt. B D. Sharma PGIMS, Rohtak during the study period from June 2012 to December 2013. All the patients who fulfilled the standard definition of nephrotic syndrome presenting in first attack or relapse whether frequent or infrequent were kept in group A. Criteria for relapse, remission, frequent relapses, infrequent relapses were as given: Nephrotic syndrome: 
characterised by protein excretion of $>40 \mathrm{mg} / \mathrm{m} 2 / \mathrm{hr}$ or a first morning protein:creatinine ratio of $>2-3: 1$ and triad of hypoalbuminemia, edema and hyperlipidemia. Relapse: reagent strip testing of first morning urine showing proteinuria of $3+$ or $4+$ for 3 consecutive days, with oedema, having been in remission previously. Remission: Reagent strip testing of first morning urine showing negative or traces of proteins for 3 consecutive days. Frequent relapses: Two or more relapses within 6 months of first remission, or more than 3 relapses in 12 months.Infrequent relapses: Three or less than 3 relapses in 12 months.

\subsection{Exclusion criteria}

Patients with possible secondary causes of nephrotic syndrome, age $<1$ year of onset or $>8$ year of onset, patients with hypothalamopituitary axis derangement, pituitary tumors, absent thyroid gland, grave's disease, thyroid gland tumors, hashimotto s disease, hypothyroidism or hyperthyroidism before the onset of nephrotic syndrome were excluded from the study. Written informed consent was taken from the legal guardian or parent of all participants. Those who denied participating in the study were excluded.

2.2 Ethical clearance was approved by Institutional Ethical Review Committee, PGIMS ,Rohtak. A total of 35 nephrotic children were included. A thorough history and elaborate clinical examination were done and recorded on a patient performa. Biochemical and other necessary investigations were done to fulfill the inclusion criteria. Serum and urine T3, T4 and TSH were measured in 35 study subjects during nephrosis and remission. Normal level was considered as Serum T3 $=0.92-2.48 \mathrm{ng} / \mathrm{ml}$, T4 $=5.95-14.7 \mathrm{ng} / \mathrm{ml}, \mathrm{TSH}=0.70-5.97 \mathrm{MIU} / \mathrm{l}$. Serum T3, T4, TSH was measured using Chemiluminescent Immunoassay (CLIA). CLIA detection using Microplateluminometers provides a sensitive and economical alternative to conventional colorimetric methodologies, such as Enzyme linked immunosorbent assays. Patient were put on standard steroid protocol and after achieving remission but before putting child on alternate day steroid, patient were clinically assessed. Then all the blood and urine investigations were repeated (Group-B). Clinical hypothyroidism was considered when the patient had clinical symptoms along with elevated TSH and lower normal level of T4. Mild hypothyroidism or sub-clinical hypothyroidismrefers to biochemical evidence of mildly elevated TSH without any other manifestations of hypothyroidism along with normal level of serum T4.All patients were treated with prednisolone according to standard protocol, $2 \mathrm{mg} / \mathrm{kg} /$ day (max $80 \mathrm{mg}$ ) for 6 weeks, followed by $1.5 \mathrm{mg} / \mathrm{kg} / \mathrm{day}$ on every alternate day for the next 6 weeks in initial attack and inrelapse cases $2 \mathrm{mg} / \mathrm{kg} / \mathrm{day}$ for 3 consecutive days urinary remission followed by $1.5 \mathrm{mg} / \mathrm{kg} /$ day onalternate day for 4 weeks. Serum T3, T4 and TSH were again measured in 35 children 4 weeks after achievement of remission and were compared with their previous values during nephrosis. We measured spot urinary T3, T4, TSH during relapse and in remission. No correlation was found between blood T3 and urinary T3. No thyroxine treatment was given to any of them. Statisticalanalysis was done by SPSS 20.0.

\section{Results}

A total of 35 cases of steroid responsive nephrotic syndrome were enrolled in the study.Analysis was done during attack/relapse and were followed up during remission. Age ranged from $2-8$ years . Our study included 18 males and 17 females. TABLE 1 shows low serum total protein and low serum albumin ,normal blood urea and creatinine and high triglycerides and total cholesterol.

Table 1: Blood Profile In Patients

\begin{tabular}{|l|l|}
\hline Patient characterstics & Mean \pm SD \\
\hline Serum alkaline phosphte & $108.63 \pm 1.987$ \\
\hline Serum protein & $3.091 \pm 0.968$ \\
\hline Albumin:globulin & $0.69 \pm 0.171$ \\
\hline Blood urea & $19.8 \pm 3.42$ \\
\hline Serum creatinine & $0.606 \pm 0.153$ \\
\hline Uric acid & $1.417 \pm 0.672$ \\
\hline Serum calcium & $8.171 \pm 0.729$ \\
\hline Serum phosphate & $3.997 \pm 0.439$ \\
\hline Serum triglycerides & $426.99 \pm 91.791$ \\
\hline High density lipoproteins & $41.11 \pm 4.262$ \\
\hline Low density lipoproteins & $40.8 \pm 3.252$ \\
\hline Total cholestrol & $396.83 \pm 103$ \\
\hline Serum albumin & $1.42 \pm 0.28$ \\
\hline
\end{tabular}

\subsection{Presenting Complaint}

Maximum patients presented with facial swelling $(80 \%)$ followed by decreased urine output $(62.85 \%)$ and by abdominal distension (31.42\%) as shown in fig 2 . 


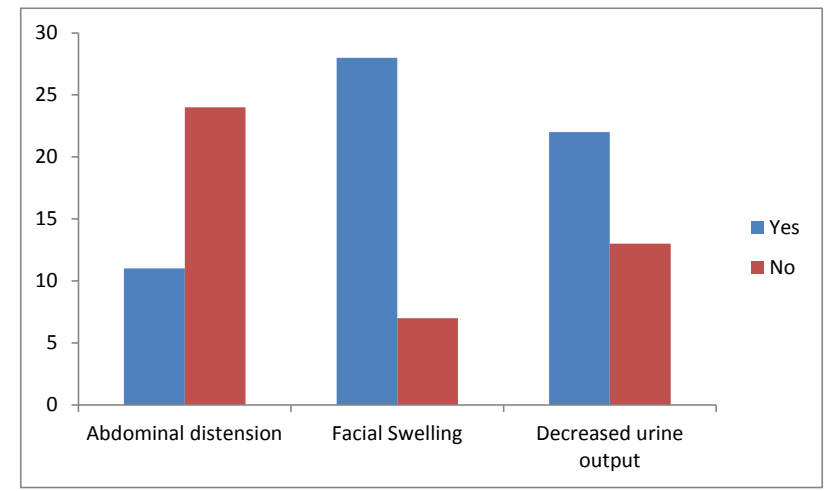

Figure 1 Presenting complaints

\subsection{Thyroid status}

In 35 children with nephroticsyndrome thyroid function status was compared during nephrosis and remission. Serum T3 and T4 level during nephrosis and during remission are within normal limits. But TSH level is significantly higher during nephrosis which normalizes during remission 6 weeks later $(8.93 \pm 3.15$ vs. $5.77 \pm 0.65 \mathrm{MIU} / \mathrm{L}, \mathrm{p}=0.002)$.

Table 2: Comparison Of Thyroid Status Before And After Treatment

\begin{tabular}{|l|l|l|l|l|l|}
\hline Thyroid hormones & During attack & During remission & T value & df & P value \\
\hline T3(ng/ml) & $0.763 \pm 0.24$ & $0.749 \pm 0.13$ & 0.316 & 34 & 0.754 \\
\hline T4(ng/ml) & $5.37 \pm 1.06$ & $5.72 \pm 0.90$ & -1.361 & 34 & 0.183 \\
\hline TSH(MIU/l) & $8.93 \pm 3.15$ & $5.77 \pm 0.65$ & 5.934 & 34 & 0.002 \\
\hline
\end{tabular}

Thyroid function status of nephrotic children during nephrosis (Table 2) shows that mean value of serum T3 $(0.763 \pm 0.24) \mathrm{ng} / \mathrm{ml}$ and T4 $(0.763 \pm 0.24) \mathrm{ng} / \mathrm{ml}$ are within normal limits during and after attack, but the mean serum $\operatorname{TSH}(8.93 \pm 3.15) \mathrm{MIU} / \mathrm{L}$ value is higher than normal during attack as shown in the scatter plot .Serum TSH $(0.763 \pm 0.24)$ levels returns to normal with resolution of proteinuria .Thyroxine supplementation is not required as it results in subclinical hypothyroidism.

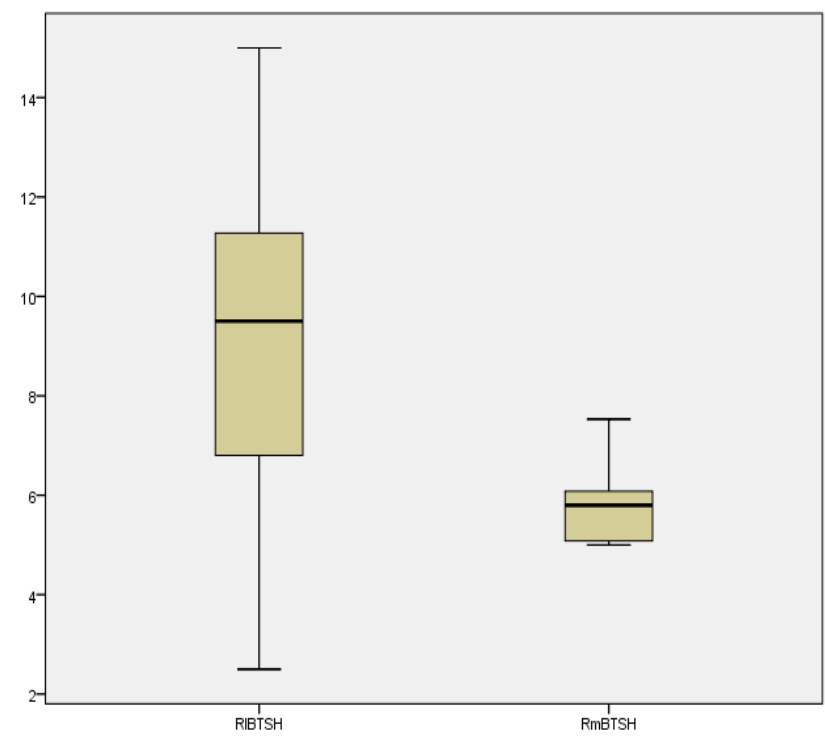

Figure 2 Box and Whisker chart showing TSH values in relapse and remission.

Serum TSH was found to be significantly increased during attack with median value of ( $9.850 \mathrm{MIU} / 1$ ) which normalized after treatment of nephrotic syndrome.(TSH=5.850 MIU/l).

3.3 The study showed a negative correlation between serum albumin and serum TSH as depicted below in the scatter plot $(\mathrm{r}=-0.480, \mathrm{p}=<0.05)$. Proteinuria resulted in loss of thyroid binding globulin as well as T3 and T4 in urine which led to decreased total T3, T4 in blood leading to increased levels of serum TSH. So with decreasing serum albumin levels serum TSH went on increasing. 
Table 3: Correlation Between Serum Tsh And Serum Albumin In Relapse

\begin{tabular}{|l|l|l|l|}
\hline \multicolumn{2}{|l|}{} & RIBTSH & S Alb \\
\hline RIBTSH & Pearson correlation & 1 & -0.480 \\
\hline S Alb & Pearson correlation & -0.480 & 1 \\
\hline
\end{tabular}

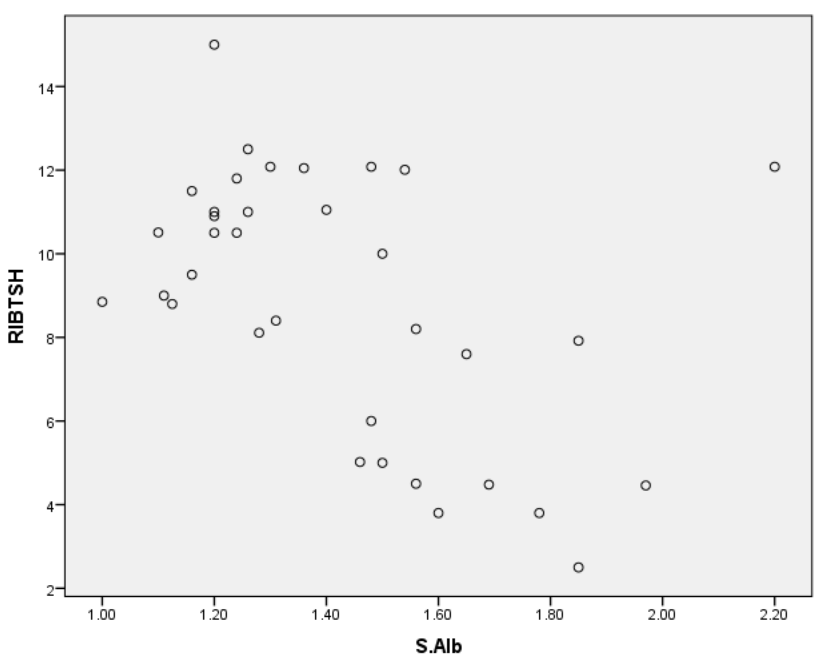

Figure 2 : Scatter plot showing correlation serum albumin and serum TSH during relapse

\section{Discussion}

Our study showed that most children with NS were clinically euthyroid with increased TSH $(8.93 \pm 3.15$ $\mu \mathrm{IU} / \mathrm{ml})$ level during nephrosis while serum T3 $(0.763 \pm 0.24 \mathrm{ng} / \mathrm{ml})$ and $\mathrm{T} 4(5.37 \pm 1.06 \mu \mathrm{g} / \mathrm{dl})$ were within normal range.The TSH $(5.77 \pm 0.65 \mu \mathrm{IU} / \mathrm{ml})$ level became normal after achieving remission. In this study the significantly raised mean serum TSH level in children with NS during nephrosis compared to the serum TSH level of same children during remission is similar to the result of Ito $\mathrm{S}$ et al. The increase in serum TSH in the study children with NS may be attributed to negative feedback due to marked urinary loss of TBG.

In our study a negative correlation has been found between serum albumin and serum TSH( $\mathrm{r}=-0.480$, $\mathrm{p}=<0.05$ ). This suggests that serum TSH level has a correlation with severity of nephroticsyndrome the more severe the nephrotic syndrome the more is hypoalbuminemia and higher is the serum TSH level in blood.

Hypothyroidism is also known to be accompanied by a decrease in glomerular filtration, hyponatremia and an alteration of the ability for water excretion, which may indirectly reduce loss of protein through urine. ${ }^{[15]}$

Our findings suggest that nephrotic syndrome patients have an increased risk of subclinical hypothyroidism. Thyroid hormones accelerate the basal metabolic rate. Thyroid function returns to normal when non thyroid illness is resolved. Proteinuria results in loss of thyroid hormones, most probably caused by loss of thyroxine-binding globulin along with T4 bound to it, thus stimulating TSH production.

Another study showed that nephrotic syndrome is associated with changes in serum TH levels. ${ }^{[16]}$ Urinary losses of binding proteins, such as TBG, transthyretin or prealbumin, albumin, and TH binded to them, result in reduction in serum total thyroxine and sometimes, in total T3 levels. These hormonal changes are related both to the degree of proteinuria and to serum albumin levels. In patients with low thyroid reserve overt hypothyroidism can develop. ${ }^{17]}$

There was no correlation between spot urinary T3,T4,TSH excretion and blood levels of T3,T4,TSH in our study. However, previous studies have demonstrated a relation between 24 hour urinary T3,T4,TSH excretion and urinary protein excretion and also with serum TSH levels. ${ }^{[18]}$

Ito $\mathrm{S}$ et al. have found significant positive correlation of daily urinary protein excretion with urinary excretion of T3, T4 and TBG. This finding suggests that high TSH level in severe nephrosis is possibly caused by massive proteinuria. ${ }^{[19]}$

Gilles et al.in 2008 reported that abnormalities in thyroid function are seen in patients with proteinuria. Specifically, TSH levels were higher in patients with proteinuric renal diseases when compared with controls. Subclinical hypothyroidism occurred more frequently in the nephritic syndrome patients. ${ }^{[12]}$

In 2011 study done by Afroz et al concluded that urinary losses of various binding proteins in nephrotic syndrome result in temporary subclinical hypothyroidism .serum T3,T4 levels were in normal range during and after attack however serum TSH level was increased during attack. In our study we also found similar results with blood T3,T4 levels in normal range before and after treatment and raised TSH levels during attack. We could not find any correlation between spot urinary T3, T4,TSH and serum T3,T4,TSH. ${ }^{[13]}$ 
In conclusion, hypothyroidism should be actively sought for in patients with nephrotic syndrome as it is a potentially health threatening and treatable complication. Given the urinary losses of multiple proteins in addition to albumin, it is important to monitor affected patients for secondary metabolic complications and to treat these complications appropriately. Children with treatment-resistant nephrotic syndrome are at particular risk for these secondary complications.

Our finding suggests that nephrotic syndrome patients have an increased risk of subclinical hypothyroidism. Thyroid hormones accelerate the basal metabolic rate and more especially oxidative metabolism in vertebrates. Excess thyroid hormones may induce tissue injury secondary to production of active oxygen species. Thyroid function returns to the normal when the nonthyroid illness is resolved.Main limitation of the study was small sample size and inability to do 24 hour urinary T3,T4,TSH and urinary thyroid binding globulin.It was concluded from this study nephrotic syndrome commonly have a state of mild or subclinical hypothyroidism during proteinuria although they are clinically euthyroid. This temporary hypothyroid state improves with remission and needs no treatment.

\section{References}

[1] Kaptein EM .Thyroid function in renal failure.Contributions to Nephrology ,50,1986,64-72.

[2] Campbell, A.G. and McIntosh N ,Endocrine gland disorders in Klenar CJ, Forfar and Arneil's text book of pediatrics:. 4th ed.London New York and Tokyo: Campbell, A.G. and McIntosh N; 1992.

[3] Katz AI \& Lindheimer MD. Actions of hormones on the kidney.Annual Review of Physiology 1977; 39: 97-133.

[4] Katz AI, Emmanouel DS \& Lindheimer MD. Thyroid hormone and the kidney. Nephron 1975; 15: $223-249$.

[5] Schussler GC. The thyroxine-binding proteins. Thyroid. 2000;10: 141-9.

[6] Kaysen GA. Non-renal complications of the nephrotic syndrome. Annu Rev Med. 1994;45:201-10.

[7] katz AI, Emmanouel DS, Marshall DL. Thyroids hormone and the kidney. Nephron. 1975;15:223-49.

[8] Iglesias P, Diez JJ. Thyroid dysfunction and kidney disease. Europeon Journal of Endocrinology. 2009;160:503-15.

[9] Matto TK. Hypothyroidism in infants with nephrotic syndrome. Pediatric Nephrology. 1994 Dec;8(6):657-9.

[10] Ito S, Kano K, Ando T, Ichimura T. Thyroid function in children with nephrotic syndrome.Pediatric Nephrology. 1994 Aug;8(4):412-5.

[11] B. U. Sawant, G. D. Nadkarni, U. R. Thakare, L. J. Joseph, and M. G. R. Rajan, "Changes in lipid peroxidation and free radical scavengers in kidney of hypothyroid and hyperthyroid pp. 1334-1337, 2003.

[12] R. Gilles, M. den Heijer, A. H. Ross, F. C. G. J. Sweep, A. R. M. M.Hermus, and J. F. M.Wetzels. Thyroid function in patients with proteinuria. Netherlands Journal of Medicine 2008, 66, 11, 483-485.

[13] Iglesias P, Diez JJ Thyroid dysfunction and kidney disease .Europeon journal of endocrinology 2009, 160,503-515.

[14] Afroz S, Khan AH, Roy DK. Thyroid function in children with nephrotic syndrome. Mymensingh Med J. 2011;20(3):407-11.

[15] Ichikawa I, Kiyama S, Yoshioka T. Renal antioxidants enzymes their regulation and function. Kidney Int 1994;45:1-9.

[16] Junglee NA ,Scanlon MF,ReesDA.Increasingthyroxine requirements in primary hypothyroidism .Don't forget the urinanalysis.Journal of Postgradraduate Medicine 2006,52,201-3.

[17] Kaptein EM, Hoopes MT, Praise M, Massry SG.TT3 metabolism in patients with nephrotic syndrome and normal GFR compared with normal subjects. Am J Physiol 1991;260:E641-50.

[18] Fonseca V, Thomas M, Kartak A, Sweny P, Moorhead JF. Lancet 1991,475-6.

[19] Sachio Ito, kenichikano,Tamotsu Ando and TohjuIchimura.Thyroid function in children with nephrotic syndrome.Pediatric Nephrology (8) ,4,1994, 412-415. 